\title{
Üniversite Öğrencilerinin Memnuniyet ve Beklentileri: Akdeniz Üniversitesi Edebiyat Fakültesi 2012-2013
}

\author{
Level of Satisfaction and the Expectations of Undergraduate Students Enrolled \\ at Akdeniz University's Faculty of Letters
}

\section{Gökhan V. KÖKTÜRK*}

Öz: Üniversite öğrencilerinin memnuniyetleri ve beklentilerinin belirlenmesi, bir yandan mutluluk ve huzurları için son derece önemli olup diğer yandan ise öğrencilerin zamanlarının büyük kısmını geçirdikleri üniversitelerde kurum kültürünün oluşması ve gelişmesi bakımından vazgeçilmez niteliktedir. Bu bağlamda 2012 ve daha sonra da 2013 öğretim yılında Akdeniz Üniversitesi Edebiyat Fakültesi bünyesinde iki ayrı araştırmada elde edilen veriler karşılaştırmalı olarak bu çalışmada değerlendirilmiştir. Yapılan analizler sonucunda ulaşılan bilgiler gençlerin etkileşimde bulundukları kurumsal yapıdan memnuniyetlerini ve beklentilerini büyük oranda ortaya koymuş ve öğrencilerin gelecek inşalarında faydalı olabilecek değişiklikleri belirleme çalışmalarına katkı sağlayıcı nitelikte olmuştur.

Anahtar sözcükler: Üniversite Öğrencisi, Memnuniyet, Beklenti, Kurumsal Yapı, Etkileşim

Abstract: Determining university students' level of satisfaction and their expectations is extremely important for the well-being and happiness of students simply because the students' positive feelings and opinions are an indispensable factor in terms of the formation and development of institutional culture in universities. In this context, the students' feelings and opinions concerning the services they obtain from Akdeniz University's Faculty of Letters were investigated through two separate research studies; one in 2012, the other in 2013. In this study, the data obtained from these two research studies was evaluated through comparing that from 2012 with that from 2013. The results showed the undergraduate students' level of satisfaction and their expectations from the institutional structure may prove helpful in improving the institution's services.

Keywords: Undergraduate Student, Satisfaction, Expectation, Institutional Structure, Interaction

\section{Giriş}

Üniversite öğrencilerinin gelecekle ilgili planları, gelecekte kurmayı tasarladıkları hayatı, düşünce bazında şekillendiren etkenlerin en önemlilerinden biri, etkileşim içinde oldukları kurumsal yapılardır. Nitekim kurumsal yapılar farkında olsak ya da olmasak da bizi çevreleyen sosyal dünyanın kimi zaman zorlayıcı, şekillendirici, hâkim kültürü benimsetici kimi zaman ise beklentileri karşılayan, özellikle gençlerin yaşamlarında fazla bir enerji harcamadan öğrenebildikleri baskın kültürün değer ve normlarına özdeşleşme yönüyle birlikte yaşamanın önemli bir bileşenidir. Dolayısıyla yakın çevremizdeki kurumsal yapıların aile, siyaset, din ve ekonomi gibi temel sosyal kurumlardan rengini alması, gençlerin kurumsal olana ilişkin görüşlerini

\footnotetext{
* Yrd. Doç. Dr., Akdeniz Üniversitesi, Edebiyat Fakültesi, Sosyoloji Bölümü, Antalya.
} gokhanvkokturk@gmail.com 
belirleyici niteliktedir.

Başka bir deyişle, gençlerin etkileşim içinde bulundukları kurumsal yapı onların etkileşimde bulundukları diğer sosyal süreçlerle etkileşim halindedir. Bu noktada etkileşim sürecinin altını çizmek önemlidir zira etkileşim çift yönlüdür, hem etkilemeyi hem de etkilenmeyi içermektedir. Dolayısıyla kurumsal olana ilişkin düşüncelerimiz; olumlu gördügümüz davranış örüntülerinin yansıması olup, sosyalleşme sürecinin önemli bir parçasıdırlar. Benzer şekilde Biren et al. (1998) belirttiği gibi; kurumsal yapı inşasında ortaya çıkabilecek olumsuz durumlar eksik bütünleşmenin veya bazılarının izolasyonunun önemli bir parçası olabilirler.

Üniversite öğrencileri söz konusu olduğunda akla ilk gelen kurumsal yapı, doğrudan etkileşim içinde bulundukları üniversitelerdir. $\mathrm{Bu}$ durum aynı zamanda öğrencilerin memnuniyet derecelerini, üniversiteden beklentilerini ve bunları doğrudan ya da dolaylı olarak etkileyen süreçleri kapsamaktadır. Kurumsal yapı inşasında, olumlu bulunmayan durumların tespitinde etkili olan ve önemli bir geribildirim aracı olan öğrencilerin memnuniyet derecelerinin ve beklentilerinin belirlenmesine yönelik bu çalışmada Akdeniz Üniversitesi Edebiyat Fakültesi öğrencileri konuyla ilgili veri kaynağı olarak belirlenmiştir. Dolayısıyla öğrencilerin memnuniyet dereceleri ve beklentileri okumakta oldukları bölüm ve fakülte düzeyinde belirlenmeye çalışılmıştır. Bunun yanında araştırmanın hiçbir aşamasında öğrencilerin memnuniyet ve beklentileri sahip olunan kimliğe göre bir başka deyişle öğrencilerin kamusal alanda kendilerini ifade ediş şekillerine göre bir kategorileştirmeye gidilmemiştir. Böylesi çalışmalar öğrencilerin aidiyet duygusunun oluşmasının önündeki engellerin ortadan kaldırılmasına yardımcı olabileceği gibi, Sarı'nın $(2013,148)$ belirttiğine göre; gelişen aidiyet duygusu akademik başarının artmasında etkili bir faktördür.

\section{Araştırma Deseni}

Akdeniz Üniversitesi Edebiyat Fakültesi öğrencilerinin memnuniyet düzeylerini ve beklentilerini belirleyebilmek amacıyla iki ayrı araştırma tasarlanmış ve uygulanmıştır. Akdeniz Üniversitesi Edebiyat Fakültesi Memnuniyet Araştırması 2012 ve Akdeniz Üniversitesi Edebiyat Fakültesi Memnuniyet Araştırması 2013 başlıkları altında yapılan bu araştırmalara Edebiyat Fakültesinin, Fen Fakültesi'nden ayrılıp geçici olarak yeni bir binaya taşınması ve bir süre sonra da Edebiyat Fakültesi'nin kendi binasına taşınmış olması, hem değişkenler açısından hem de uygulama şartları açısından araştırmalara rengini veren en önemli etken olmuştur.

Öğrencilerin memnuniyetlerinin, beklentilerinin belirlenebilmesi amacıyla açık-uçlu ve kapalı-uçlu sorulardan oluşan bir anket formu dizayn edilmiştir. Bu form öğrencilerin düşüncelerini etkileyen süreçleri değerlendirebilmek amaciyla demografik sorulardan, öğrencilerin bölümlerinden ve fakültelerinden beklentilerinin kendi ifadeleriyle, cümleleriyle öğrenilebilmesi amacıyla açık-uçlu sorulardan ve öğrencilerin katılım derecelerini belirttiği Likert Ölçeği tipi sorulardan oluşmuştur.

Bu bağlamda; 2012 y1lı için örgün öğretim ve ikinci öğretim toplam 1866 olan öğrenci sayıs1 araştırma evrenini oluşturmuş, örgün öğretim öğrenci sayısı olan 1448 ise, çalışma evrenini oluşturmuştur. Öğrencilerin okudukları bölüm kota kriteri olarak belirlenerek, her bölümün toplam öğrenci sayısının, fakülte toplam öğrenci sayısı içindeki ağırlığı kadar örneklem grubuna öğrenci dâhil edilmiştir. Bu oranlar şu şekildedir; 
Tablo 1. Kota Kriterlerine Göre Seçilerek Araştırmaya Dâhil Edilmiş Öğrencilerin Oranları

\begin{tabular}{|l|c|c|}
\hline \multirow{2}{*}{} & 2012 & 2013 \\
\cline { 2 - 3 } & \multicolumn{2}{|c|}{$\%$} \\
\hline Arkeoloji Bölümü & 16,7 & 9,8 \\
\hline Batı Dilleri ve Edebiyatları Bölümü & - & 2 \\
\hline Eski Yunan Dili ve Edebiyatı Bölümü & 11,6 & 6,4 \\
\hline Felsefe Bölümü & 28,3 & 22,5 \\
\hline Gerontoloji Bölümü & 4,5 & 0.2 \\
\hline Sanat Tarihi Bölümü & 0,3 & 7,6 \\
\hline Sosyoloji Bölümü & 14,7 & 10,3 \\
\hline Tarih Bölümü & 21,9 & 19,7 \\
\hline Türk Dili ve Edebiyatı Bölümü & 2 & 21.6 \\
\hline
\end{tabular}

Burada gözden kaçırmamamız gereken husus, öğrencisi olmayan veya sadece 1. ve 2. sınıfi olan bölümlerin olduğudur.

Öğrencilere anket uygulamasında dikkat edilen noktalardan bir tanesi de lisans öğrencilerinin örneklem grubuna her düzeyde katılımını gerçekleștirmek ve bunu analizlere yansıtmak olmuştur. Bu doğrultuda; 2012 yılı için toplam 610 öğrenciden \%27.7'si birinci sınıf, \%25.6's1 ikinci sınıf, \%26.1'i üçüncü sınıf, \%18.2'si dördüncü sınıf ve \%1.6'sı da artık yıl olarak dağılım göstererek örneklem grubuna yansımıştır. 2013 y1lı için ise; bu oranlar \%31.6 ile birinci sınıf, $\% 31.8$ ile ikinci sınıf, \%11.3 ile üçüncü sınıf ve \%24 ile son sınıflar şeklindedir.

Gerek anket formunun hazırlanmasında gerek soruların tasarlanmasında öğrenciler ile yapılan görüşmeler hem yönlendirici hem de belirleyici nitelikte olmuştur. Bunun yanında unutulmamalıdır ki elde edilen bulguları tüm üniversiteye ya da bütün üniversite öğrencilerine genelleyebilmek mümkün değildir. Bunu bilmek yapılan araştırmaların farkındalık düzeylerinin oldukça yüksek olduğunu göstermektedir.

\section{Karşılaştırmalı Değerlendirme}

Öğrencilerin etkileşim içinde bulundukları kurumsal yapıya ilişkin düşüncelerinin şekillenmesinde etkili olan süreçleri tanımlayabilmek amacıyla, öğrencilerin cinsiyet dağılımları oldukça etkin bir değişken olarak araştırma sürecinde yer almıştır. Nitekim yapılan her iki araştırmada da Kadın \%60, Erkek \%40 oranlarında edebiyat fakültesi öğrencileri açısından dengeli bir dağılım elde edilmiştir.

Öğrencilerin ve ailelerinin gelir düzeyleri, toplumsal statüleri ve bu doğrultuda şekillenen beklenti ve memnuniyetlerini belirlemekte büyük önem arz etmektedir. Yapılan her iki araştırmayı göz önüne alarak öğrenci ailelerinin düşük gelire sahip olduklarını söylemek mümkün gözükmektedir. Bu durum aynı zamanda; Öğrenci ailelerinin parasal baskı altında olduklarının ve öğrencilerin kitap ve diğer ders materyalleri edinmesinde ekonomik durum nedeniyle eksiklikler ortaya çıkarmaktadır (Bennett 2003, 126). Bu anlamda öğrenci aileleri ve öğrencilerin aylık ortalama gelirleri aşağıdaki gibi belirlenmiştir: 
Tablo 2. Edebiyat Fakültesi Öğrenci ve Ailelerin Aylık Ortalama Geliri (\%)

\begin{tabular}{|l|l|c|l|c|c|}
\hline \multicolumn{1}{|c|}{ 2012 Gelir (TL) } & Aile & Öğrenci & \multicolumn{1}{|c|}{ 2013 Gelir (TL) } & Aile & Öğrenci $^{*}$ \\
\hline 0-650 aras1 & 18.8 & 91.6 & $0-750$ aras1 & 20.71 & 77.88 \\
\hline 651-1300 aras1 & 47.2 & 6.8 & $751-1500$ aras1 & 30.62 & 8.85 \\
\hline 1301-1950 aras1 & 17.8 & 1.1 & $1501-2250$ aras1 & 25.19 & - \\
\hline 1951-2600 aras1 & 8.5 & 0.5 & $2251-3000$ aras1 & 8.50 & - \\
\hline 2601-3250 aras1 & 4.2 & - & $3001-3750$ aras1 & 3.19 & - \\
\hline 3251-3900 aras1 & 1.0 & - & $3751-4500$ aras1 & 1.95 & - \\
\hline 3901-4550 aras1 & 1.5 & - & $4501-5250$ aras1 & 2.12 & - \\
\hline 4551 ve üstü & 1.0 & - & 5251 ve üstü & 4.96 & - \\
\hline
\end{tabular}

* Bu soruyu \% 11.15 oranında öğrenci cevapsız bırakmıştır. Diğer kategorilerdeki cevaplar anlamsızdır.

Üniversite öğrencilerinin kurumsal yapıyla ilgili düşüncelerinin büyük oranda kaynağı olan okumakta oldukları bölümden kaynaklı yaşantıları, öğrencilerin okumakta oldukları bölümü tercih etmeleri ve bunun nedenlerini belirlememizin önemini ortaya koymaktadır. Bu bağlamda; yürütülen araştırmalarda öğrencilerin okumakta oldukları bölümü tercih etme nedenleri arasında 2012 y1lı için en yüksek oranda \%25.4 ile "puanım bu bölüme yettiği için" yanıtı alınmış sonra sırası ile \%18.5 ile "ögretmen olmak", \%16.4 ile "geleceği olan bir meslek edinmek", \%9.3 ile “üniversite mezunu statüsü kazanmak”, \%2.3 ile "ailemin isteğini yerine getirmek" yantları alınmıştır. Aynı şekilde 2013 yılında yapılan araştırmada ise; en yüksek oranda \%28.67 ile "ögretmen olmak" yanıtı alınmıştır. Sonra sırasıyla; \%22.65 ile "puanım bu bölüme yettiği için", \%12.74 ile "geleceği olan bir meslek edinmek", \%9.91 ile "üniversite mezunu statüsü kazanmak”, \%3.54 ile “ailemin isteğini yerine getirmek" yanıtları alınmıştır.

Bu cevap oranlarından yola çıkarak bölüm tercihinde ailenin isteğinin etkisinin alt düzeyde olduğu şeklinde bir yorum yapılabilir. Ancak öğrenci ailelerinin düşük gelir düzeyine sahip oldukları ve buna bağlı olarak öğrencilerin bölüm tercihlerini yaparken "ögretmen olmak” ya da "üniversite mezunu statüsü kazanmak" şeklindeki yanıtlarındaki zımni aile etkisini gözden kaçırmamak gerekir.

Öğrencilerin katılım derecelerinin sorulduğu likert tipi sorulara alınan cevaplar madde analizi stratejisi ile değerlendirilmiş böylelikle de her iki yılda alınan cevaplar karşıllaştırılmış ve öğrencilerin etkileşimde bulundukları kurumsal yapıyla ilgili memnuniyet ve beklentileri ortaya çıkarılmaya çalışılmıştır.

$\mathrm{Bu}$ doğrultuda en yoğun katılımın sergilendiği "Bölümümde alanımla ilgili zorunlu staj dersi olmalı" ifadesine 2012 y1lında \%52 Tamamen Katılıyorum, \%20 Katıliyorum yanıtı alınırken 2013 yılında ise; \%55 Tamamen Katılıyorum, \%16 Katılıyorum cevapları alınmıştır. Aynı şekilde etkileşimde bulundukları kurumsal yapının en önemli unsurlarından olan öğretim elemanlarıyla ilgi olarak "Hocalar dersler için yeterli bilgiye sahiptir" ifadesine yüksek oranlarda katıldıklarını belirtmişlerdir. Şöyle ki; 2012 yılında bu ifadeye \%52.8 Tamamen Katılıyorum, \%34.5 Katılıyorum cevabı alınmış 2013'de de \%40 Tamamen Katılıyorum, \%32 Katılıyorum cevabı alınmıştır.

Zorunlu staj dersi isteği fakültede neredeyse bütün öğrencilerin dile getirdiği bir beklenti halindedir. Gerek yapılan görüşmelerde gerekse uygulanan anketlerde ulaşılan bilgiler sonucunda bu beklentiyle ilgili olarak, özel sektörde staj imkânı, kamu sektöründe iş imkânı 
istenmektedir saptaması yapılabilir.

Öğrencilerin memnuniyet düzeylerini ve aynı zamanda beklentilerini de yansıtan "Dersler programda belirtilen süreler kadar sürmektedir" ifadesi 2012 yılında \%39.7 Katılmıyorum ve \%22.9 Hiç Katılmıyorum şeklinde cevaplanmış, 2013 yılında ise \%38 Tamamen Katılıyorum ve \%27 Kısmen Katılıyorum yanıtları alınmıştır. Bu sonuçlardan da anlaşılacağı üzere, öğrenciler etkileşimde bulundukları kurumsal yapıda kendi bakış açılarından derslerin kısa sürdüğü konusunda kanaatlerini belirtmişler ve derslerin programlarda belirtilen sürelerde yapılması yönünde beklentilerini belirtmişlerdir.

Üniversite öğrencilerinin kendilerinin de önemli gördükleri ve gelecek inşalarında önemli bir unsur olan yabancı dil konusunda, etkileşim içinde bulundukları kurumsal yapının önemli bir yapı taşı olan öğretim elemanlarıyla ilgili olarak "Bölüm hocaları yabancı dil konusunda hassasiyet göstermemektedir" ifadesine 2012 y1lı verilerinde \%16.7 Tamamen Kat1liyorum, \%16 Katılıyorum, \%19 Kararsızım, \%29.2 Katılmıyorum, \%19.1 Hiç Katılmıyorum şeklinde cevap vermişlerdir. Aynı ifadeye 2013 y1lı verilerinde ise; \%23 Tamamen Katılıyorum, \%17 Kısmen Katılıyorum, \%17 Kararsızım, \%20.3 Katılmıyorum, \%18.4 Hiç Katılmıyorum şeklinde cevap vermişlerdir.

Genellikle sosyal paylaşım siteleri ve e-posta için kullanıldığ gözlenen ortak kullanıma tahsis edilen bilgisayarların sayısının yeterli olup olmadığı ve aynı zamanda fakülteden memnuniyeti de yansıtan "Edebiyat Fakültesi bünyesinde ögrencilerin kullanımı için yeterli sayıda bilgisayar bulunmaktadır" ifadesine 2012 y1lı için \%15.3 Tamamen Katıllyorum, \%31.4 Katılıyorum, \%6.5 Kararsızım, \%30.7 Katılmıyorum, \%16.1 Hiç Katılmıyorum şeklinde yanıtlar alınırken, 2013 yılında \%16.3 Tamamen Katılıyorum, \%17.1 Kısmen Katılıyorum, \%9.6 Kararsızım, \%25 Katılmıyorum, \%34.6 Hiç Katılmıyorum şeklinde yanıtlar alınmıştır.

Öğrencilerin moral motivasyonu ve aidiyet duygularının olumlu yönde gelişimi açısından etkili bir unsur olan fakülte binasının fiziki yapısıyla ilgili olarak verilen "Fakülte binası uygun fiziki şartlara sahiptir" ifadesine 2012 yılı araştırmasında; \%31.9 Tamamen Katılıyorum, \%35.1 Katılıyorum şeklinde olukça yüksek oran toplamı elde edilmiştir. 2013 y1lı araştırmasında öğrencilerin \%35’i Tamamen Katılıyorum, \%24’ü Katılıyorum şeklinde yanıt vermişlerdir.

Öğrencilerin isteklerini ve şikayetlerini etkileşimde bulundukları kurumsal yapının yöneticilerine iletebilme kolaylıkları, yaşanılan sürecin etkileşim boyutunda diğer bir deyişle yöneticileri etkileme ve yöneticilerden etkilenme oluşmasına yol açmaktadır. Nitekim öğrenciler bu durumu anlamlandırabilmeye yönelik "Fakülte yönetimi ile ögrenciler arasında kolayca iletişim sağlanmaktadır" ifadesine 2012 araştırmasında \%18.2 Tamamen Katılıyorum, \%35.4 Katılıyorum, \%17.4 Kararsızım, \%14.6 Katılmıyorum, \%11.0 Hiç Katılmıyorum şeklinde yanıtlar verirken, 2013 yılında \%13.3 Tamamen Katılıyorum, \% 18.9 Kısmen Katılıyorum, \%23 Kararsızım, \%17 Katılmıyorum, \%27.8 Hiç Katılmıyorum şeklinde yanıtlar vermişlerdir.

Üniversite öğrencilerinin bağlı bulundukları fakülte ve okudukları bölümden memnuniyet ve beklentilerinin niteliği açısından aynı zamanda bağlı bulundukları fakültenin vitrini sayılması bakımından öğrenci işleri birimi önem arz etmektedir. Bu doğrultuda öğrenciler "Öğrenci işleri personeli ögrencilere iyi davranmaktadır" ifadesine 2012 y1lı araştırmasında \%16.8 Tamamen Katılıyorum, \%30.0 Katılıyorum, \%8.6 Kararsızım, \%18.3 Katılmıyorum, \%26.3 Hiç Katılmıyorum şeklinde yanıtlar verirken, 2013 y1lında \%20 Tamamen Katıliyorum, \%19 Kısmen Katılıyorum, \%18 Kararsızım, \%15 Katılmıyorum, \%25 Hiç Katılmıyorum şeklinde yanıtlar vermişlerdir.

Öğrencilere yöneltilen açık-uçlu sorularda, öğrencilerin düşüncelerini kendi ifade tarzı ve 
kendi cümleleriyle belirtmeleri istenmiş böylelikle öğrencilerin konulara yaklaşım açılarının göz ardı edilmemesi amaçlanmıştır. Bu bağlamda öğrencilere bölüm, fakülte ve sınırlı olarak da üniversite ve yapılan bu çalışmayla ilgili memnuniyet düzeylerini arttıracak, yapılmasını veya olmasını istedikleri üzerine açık-uçlu sorular olarak sorulmuştur. Bu doğrultuda sorulan sorulara alınan cevaplar göz önüne alındığında bölüm memnuniyetinin artması konusunda 2012 araştırması ve 2013 araştırmasında en fazla yazılan ifade zorunlu staj dersinin olması yönündedir. İkinci en sıklıkla yazılan ifade 2012 yılında İngilizce hazırlık olması yönündedir, 2013 yılında ise ikinci olarak en sık ifade hazırlık olması yönündedir. Üçüncü en fazla ifade ise 2012 yılı için; bölüm dersleri arasında formasyon derslerinin olmas1, 2013'de ise derslerde sahaya çıkılması şeklindedir.

Aynı şekilde fakülte memnuniyetlerini artıracak dolayısıyla beklentilerini de içeren görüşlerinin açık-uçlu olarak sorulan sorulara 2012 yılında \%70 oranında ortak kullanıma açık bilgisayar sayısının arttırılması yönünde, ikinci en sıklıkla öğrenci işleri biriminin daha etkin olması yönünde, üçüncü en sık olarak gözlenen ifade ise kantin ve sınıfların büyük olması yönündedir. 2013 yılında ise yeni binaya taşınmış olmanın etkisiyle, en sıklıkla belirtilen ifade temizlik ve hijyene daha fazla dikkat edilmesi, ikinci olarak bina çevre düzenleme ve aydınlatmanın yapılması yönündedir. Üçüncü en sıklıkla belirtilen ifade ise ortak kullanılan bilgisayar sayısının arttırılması şeklindedir.

Öğrencilere genel olarak fikir vermesi amaciyla 2012 yılında, Akdeniz Üniversitesini sosyal bilimler alanında etkin bulup bulmadıkları sorulmuş ve \%29.6 evet, \%21.6 hayır ve \%48.7 kısmen cevabı alınmıştır.

2013 yılında ise öğrencilere bu çalışmanın kendileri için yararlı olup olmayacağı hakkındaki görüşleri sorulmuş $\% 27.96$ evet, $\% 47.79$ kısmen cevabı alınmıştır. Bu yüksek oranlardaki olumlu görüş, bu tür çalışmaların sonuçlarının üniversite yönetimi ve dekanlık tarafından dikkate alındığının bir göstergesidir.

\section{Sonuç}

Yapılan çalışmalar neticesinde ulaşılan bilgiler gençlerin etkileşimde bulundukları kurumsal yapıdan memnuniyetlerini ve beklentilerini büyük oranda ortaya koyarak gelecek inşalarında faydalı olabilecek değişiklikleri belirleme çalışmalarına katkı sağlayıcı nitelikte olmuştur. Bu bağlamda; öğrencilerin genel demografik özellikleri ile hayal dünyaları arasında, fiziki yap1 yeterliliği ile memnuniyet düzeyleri arasında, öğrenci-öğretim üyesi ilişkileri ile yeterlilikler arasında, öğrenci-idari personel ilişkileri ile davranış örüntüleri, bölüm memnuniyeti ve fakülte memnuniyeti ile aidiyet duygusu arasında, öğrenci düşünce ve istekleri ile beklentileri arasında stratejik bağlantılar kurmak suretiyle, öğrencilerin vakitlerinin çoğunu geçirdikleri kurumsal yapıyla etkileşim düzeyleri belirlenmiştir.

Öğrenci aileleri ile öğrencilerin aylık ortalama gelirlerinin düşük olması, çoğu öğrencinin Anadolu'nun gelir düzeyi bakımından mütevazı yerlerinden Antalya'ya okumak için gelmiş olması dolayısıyla büyük ve turistik bir şehirde yaşam tecrübesi edinebilmek için yeterli maddi olanaklardan yoksun olmaları, öğrencilerin mevcut olanaklarından daha iyisini bekleme, talep etme ve hayal etmelerini de oldukça sade ve sıradan hale getirmektedir. Nitekim öğrencilerin beklentilerini değerlendirdiğimizde, hayal dünyalarının dar olduğu saptamasını yapmak mümkün gözükmektedir.

Öğrencilerin fiziki yapı memnuniyetlerinin ana belirleyicisi olarak sınıfların büyüklüğünün öne çıkması öğrencilerin memnun olmaları için engelli düzenlemelerini, atölyeleri, amfileri, konferans salonlarını, görsel salonlarını, okuma salonlarını, bilgisayar laboratuarlarını vb. 
fiziksel yapı unsurlarını dikkate almadıklarını ve bu yönde taleplerinin olmaması durumunu da beraberinde getirmektedir. Sonuç olarak öğrencilerin fiziki yapıda kendilerine sunulanlarla yetindikleri görülmüştür.

Yapılan araştırmalarda öğrenciler, derslerine giren hocaları yeterli gördüklerini yüksek oranlarda belirtmişlerdir. Ancak bu durumu tersten okuduğumuzda öğrencilerin yetersiz olduklarını görebiliriz. Nitekim öğrenciler yapılan araştırmalarda yabancı kaynak, güncel bilgi, gündeme ilişkin tartışma ortamının sağlanması v.b. talepleri belirtmemişlerdir.

Öğrenci ve idari personel arasındaki ilişki geleneksel davranış kalıplarının etkisi altındadır. Anadolu'dan ailelerinden ayrılıp üniversiteye gelen öğrenciler kurumlaşmış modern bir ilişki ağı yerine geleneksel davranış kalıpları içinde davranmakta ve aynı biçimde davranışları da idari personelden beklemektedirler. Bu beklentinin kökeninde; öğrencilerin kendilerini rahat, huzurlu ve güvende hissetme ihtiyacı vardır. Bu durum aynı zamanda kurumsal kültürün oluşması ve gelişmesi açısından önemlidir. Bu etkileşim süreci sonucunda ortaya çıkan aidiyet duygusu, öğrencilerin gelecek inşalarında önemli bir paya sahiptir.

Sonuç olarak; özel sektör ve üniversite hayatını staj olanağı ile iç içe kurgulamak isteyen öğrenciler konjonktürel kaygılarının etkisiyle kamu sektörüne yönelmekte ve öğretmen olabilmeyi kendilerine hedef olarak belirlemektedirler.

\section{KAYNAKÇA}

Boone H. N. \& Boone D. A. (2012). “Analyzing Likert Data”. Journal of Extension 50/2 Nisan (2012). http://www.joe.org/joe/2012april/tt2.php.

Ekinci C. E. \& Burgaz B. (2007). "Hacettepe Üniversitesi Öğrencilerinin Bazı Akademik Hizmetlere İlişkin Beklenti ve Memnuniyet Düzeyleri”. Hacettepe Üniversitesi Eğitim Fakültesi Dergisi 33 (2007) 120-134.

GÜADEK (2012). T.C. Gazi Üniversitesi, Memnuniyet Araştırma Raporu. Ankara. http://researchadvisors.com. (2015).

Nagda B. A., Gregerman S. R., Jonides J., von Hippel W. \& Lerner, J. S. (1998). "Undergraduate Student-Faculty Research Partnerships Affect Student Retention”. The Review of Higher Education, 228/1 (1998) 55-72.

Neuman L. (2003). Social Research Methods. Boston 2003.

Roger B. (2003). "Determinants of Undergraduate Student Drop Out Rates in a University Business Studies Department”. Journal of Further and Higher Education 27/2 (2003) 123-141, DOI: 10.1080/ 030987703200065154.

Sarı M. (2013). "Lise Öğrencilerinde Okula Aidiyet Duygusu". Anadolu Üniversitesi Sosyal Bilimler Dergisi, Bahar 13/1 (2013) 147-160. 